\title{
Vascular endothelial growth factor is an autocrine survival factor for breast tumour cells under hypoxia
}

\author{
MARTIN P. BARR, DAVID J. BOUCHIER-HAYES and JUDITH H. HARMEY \\ Department of Surgery, Royal College of Surgeons in Ireland, \\ Education and Research Centre, Beaumont Hospital, Dublin 9, Ireland
}

Received April 6, 2007; Accepted June 5, 2007

\begin{abstract}
Vascular endothelial growth factor (VEGF) is produced by most tumour types and stimulates the growth of new blood vessels in the tumour. The expansion of a solid tumour ultimately leads to the development of hypoxic regions, which increases VEGF production and further angiogenesis. In this study, we examined the role of VEGF in the survival of breast tumour cells under hypoxia. Murine 4T1 and human MDA-MB-231 tumour cells were cultured under normoxic and hypoxic growth conditions in the presence or absence of VEGF neutralising antibodies. Apoptosis was assessed in addition to changes in expression of the anti- and pro-apoptotic proteins, Bcl-2 and Bad, respectively. The effect of hypoxia on the novel VEGF receptor, NP1 (neuropilin-1) and the role of the PI3K (phosphatidylinositol-3-kinase) signalling pathway in response to VEGF were examined. VEGF blockade resulted in direct tumour cell apoptosis of both tumour cell lines under normoxia and hypoxia. While blocking VEGF resulted in a downregulation of hypoxia-induced $\mathrm{Bcl}-2$ expression, there was a significant increase in the pro-apoptotic protein Bad relative to cells cultured under hypoxia alone. Both hypoxia and VEGF phosphorylated Akt. Neutralising antibodies to VEGF abrogated this effect, implicating the PI3K pathway in VEGF-mediated cell survival of mammary adenocarcinoma cells. This study demonstrates that VEGF acts as a survival factor not only for endothelial cells as previously thought, but also for some breast tumour cells, protecting them from apoptosis, particularly under hypoxic stress. The data presented provide an additional rationale for combining anti-VEGF strategies with conventional anti-cancer therapies such as chemotherapy and radiotherapy.
\end{abstract}

\section{Introduction}

As a solid tumour grows, its vascular supply becomes inadequate resulting in a reduction in tissue oxygen tension.

Correspondence to: Dr Judith Harmey, Present address: Department of Molecular and Cellular Therapeutics, Royal College of Surgeons in Ireland, St. Stephen's Green, Dublin 2, Ireland E-mail: jharmey@rcsi.ie

Key words: vascular endothelial growth factor, hypoxia, phosphatidylinositol-3 kinase, apoptosis, survival
Tumour hypoxia has been directly measured in a variety of human cancers. In studies of head and neck carcinomas, it was shown that hypoxia correlated with a lower probability of disease-free survival $(1,2)$. A significant correlation between tumour metastasis and hypoxia was also demonstrated in clinical studies of soft tissue sarcomas (3) and cervical carcinoma (4). These findings suggest that hypoxia results in more aggressive tumour behaviour in a number of tumour types by altering fundamental, physiological important pathways. In addition, hypoxia is a therapeutic obstacle as it renders tumours resistant to conventional anti-cancer therapies such and chemotherapy and radiotherapy (5-7). Elevated tumour interstitial fluid pressure has also been shown to be responsible, at least in part, for the poor penetration and heterogenous distribution of therapeutic agents and nutrients to solid tumours (8).

Angiogenesis, the growth of new vessels from the preexisting vasculature, is thought to be driven largely by tumour hypoxia. Furthermore, the spread of malignant tumour cells from the primary neoplasm to distant sites is influenced by the angiogenic potential and oxygenation status of the tumour $(9,10)$. Tumour cells exposed to hypoxia show increased expression of the pro-angiogenic protein, VEGF (vascular endothelial growth factor) (11). Transient hypoxia promotes the development of metastases in melanomas expressing low VEGF levels by upregulating the expression of VEGF, thereby enhancing the angiogenic potential of tumour cells (12).

Inhibition of tumour growth in several tumour types using blocking antibodies against VEGF has been documented (13-15). Increases in the apoptotic fraction of tumour cells and a reduction in vascular density and permeability have been shown to result from neutralisation of VEGF or suppression of VEGF expression (16). Emerging evidence indicates that, in addition to its role as an endothelial cell mitogen, VEGF also protects tumour cells from apoptosis (17-19). Although there have been a number of studies highlighting the role of VEGF as a survival factor for endothelial cells through a number of mechanisms such as the induction of Bcl-2 (20), interactions with integrins (21) and sustained angiogenesis (22), the exact mechanisms of VEGF signalling in tumour cells remain unclear.

\section{Materials and methods}

Cell lines. The murine mammary adenocarcinoma 4T1 cell line was generously provided by Dr Fred Miller (Duke University, 
NC, USA). The MDA-MB-231 human mammary adenocarcinoma cell line was purchased from the American Tissue Culture Collection (ATCC). 4T1 tumour cells were maintained in Roswell Park Memorial Institute medium (RPMI-1640) in a humidified atmosphere of $5 \% \mathrm{CO}_{2}$ in air at $37^{\circ} \mathrm{C}$. MDAMB-231 cells were maintained in sealed flasks with Leibovitz (L-15) culture medium at $37^{\circ} \mathrm{C}$. All media were supplemented with $10 \%$ heat-inactivated fetal bovine serum (FBS), penicillin (100 U/ml) and streptomycin (100 $\mu \mathrm{g} / \mathrm{ml})$ (Gibco BRL, UK). All cells were maintained as monolayer cultures and exponentially growing cultures were used for experiments.

TUNEL assay. Apoptosis was assessed using the in situ cell death detection kit (Roche Diagnostics, Germany). 4T1 and MDA-MB-231 tumour cells were seeded on plastic (Gibco BRL) or glass (Becton Dickinson, CA, USA) chamber slides, respectively, at a concentration of $5 \times 10^{4}$ cells/chamber in triplicate, for each condition. Cells were allowed to recover overnight and then treated for $24 \mathrm{~h}$ under normoxia $\left(21 \% \mathrm{O}_{2}\right)$ or hypoxia $\left(2 \% \mathrm{O}_{2}\right)$ in the presence or absence of VEGF neutralising antibodies $(1 \mu \mathrm{g} / \mathrm{ml})$, with FBS in the culture media reduced to $1 \%$ to increase baseline levels of apoptosis in 4T1 and MDA-MB-231 tumour cells. Cells were fixed in 100\% (v/v) methanol and stained according to the manufacturer's instructions. Apoptotic cells were counted in five fields and scored per sample $(n=3)$.

VEGF ELISA. 4T1 and MDA-MB-231 cells were cultured under normoxia $\left(21 \% \mathrm{O}_{2}\right)$ or hypoxia $\left(2 \% \mathrm{O}_{2}\right)$ for $24 \mathrm{~h}$. Cell culture supernatants were collected and any debris was pelleted by centrifugation at $300 \mathrm{x}$ g for $5 \mathrm{~min}$. Cells were washed three times in PBS, lysed and total protein measured using the bicinchoninic acid (BCA) assay. VEGF production by 4T1 and MDA-MB-231 cells was measured using the Quantikine murine or human VEGF ELISA kits (R\&D Systems Europe, Abingdon, UK), respectively. Results were expressed as pg $\mathrm{VEGF} / \mu \mathrm{g}$ of total cell protein.

Western immunoblotting. Cells were washed three times in PBS and lysed for $1 \mathrm{~h}$ on ice in $1 \mathrm{ml}$ of lysis buffer [5 mM Tris-HCl, pH 7.4, $150 \mathrm{mM} \mathrm{NaCl}, 5 \mathrm{mM}$ EDTA, $0.5 \%$ (v/v) Triton X-100, 0.5\% (w/v) SDS, 0.5\% (w/v) deoxycholic acid, $1 \mathrm{mM}(\mathrm{w} / \mathrm{v})$ phenylmethylsulphonyl fluoride]. For experiments examining phosphorylated Akt, $1 \mathrm{mM}$ sodium orthovanadate was added to the lysis buffer. Total protein concentration was determined using the BCA assay according to the manufacturer's instructions (Pierce, IL, USA). Proteins $(50 \mu \mathrm{g})$ were size-fractionated by $12 \%(\mathrm{Bcl}-2, \mathrm{Bad}$ and NP1) or $8 \%$ (phosphorlyated Akt) SDS-PAGE and transferred to nitrocellulose membranes (PALL Corporation, FL, USA). Membranes were incubated in blocking buffer [5\% non-fat dry milk in Tris-buffered saline (25 mM Tris- $\mathrm{HCl}, \mathrm{pH} 7.6$, $150 \mathrm{mM} \mathrm{NaCl}$ ) containing $0.1 \%$ (v/v) Tween-20 (TBST)] for $1 \mathrm{~h}$ at room temperature and incubated for $60 \mathrm{~min}$ with the appropriate primary antibody that was both murine and human reactive. Blots were probed using anti-NP1 antibody (Santa Cruz Biotech, CA, USA) diluted 1:100, anti-Bad antibody (BD Pharmingen, UK) diluted 1:500, anti-Bcl-2 (Santa Cruz Biotech, CA, USA) diluted 1:200 and anti-phospho Akt (Cell Signalling, MA, USA) diluted 1:1000. All incubations of
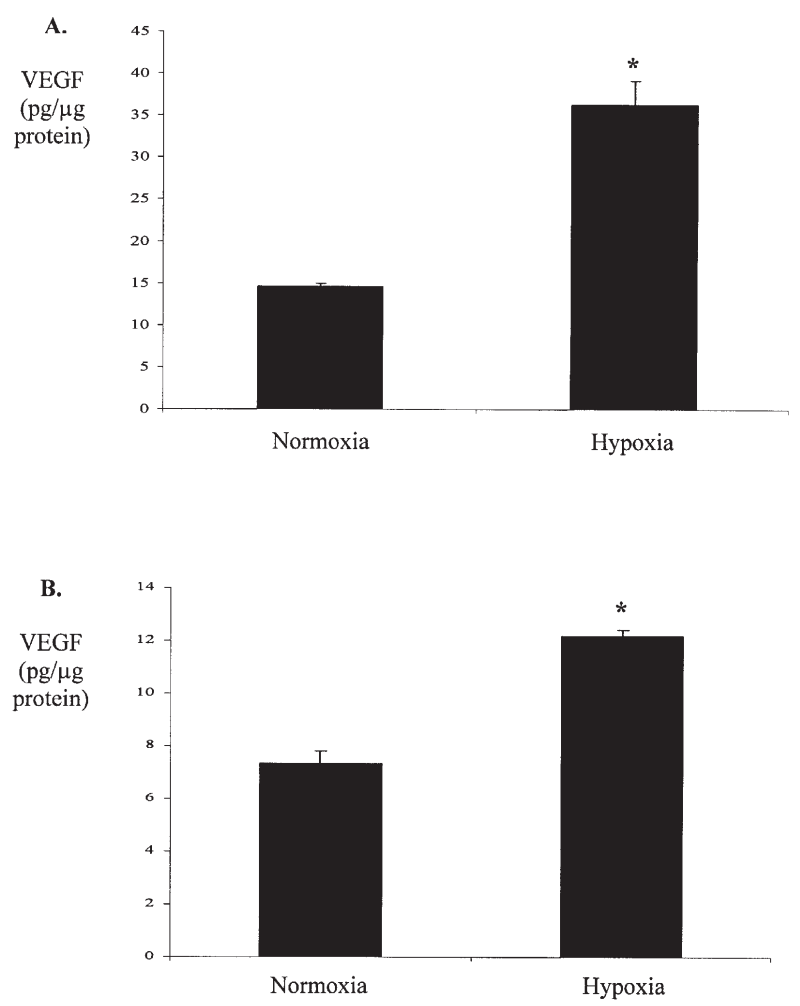

Figure 1. Hypoxia induced VEGF production by breast tumour cells. 4T1 (A) and MDA-MB-231 (B) tumour cells were cultured under normoxia $\left(21 \% \mathrm{O}_{2}\right)$ or hypoxia $\left(2 \% \mathrm{O}_{2}\right)$ for $24 \mathrm{~h}$. Cell culture supernatants were collected and VEGF protein was measured by ELISA. Total cell protein was quantified by BCA assay and VEGF expressed as $\mathrm{pg} / \mu \mathrm{g}$ cell protein. Data are expressed as the mean \pm SEM. Statistical analysis was carried out by unpaired Student's t-test $\left({ }^{*} \mathrm{p}<0.05\right.$, hypoxia vs normoxia, $\left.\mathrm{n}=3\right)$.

primary antibodies were carried out in 5\% blocking buffer. Following six 5-min washes in TBST, membranes were incubated for $90 \mathrm{~min}$ with the appropriate horseradish peroxidase-conjugated secondary antibody (Dako, Glostrup, Denmark), diluted 1:2000 in TBST. Bound antibody was detected using enhanced chemiluminescence (ECL) (Pierce). NP1, Bad and Bcl-2 blots were stripped and equal loading was confirmed using a $B$-actin antibody (Merck Biosciences, UK) diluted 1:20,000 in 5\% blocking buffer. Phospho-Akt blots were also stripped and re-probed using antibody to total Akt (BD Pharmingen), diluted 1:200 in 5\% blocking buffer.

Statistical analysis. Statistical comparison between groups was carried out using analysis of variance (ANOVA) with Scheffe post-hoc correction to examine any overall differences between groups. Where the means of two data sets were compared, an unpaired Student's t-test was used. Data is graphically represented as mean \pm SEM. All data was analysed using the SPSS $^{\text {тм }}$ (SPSS Inc., IL, USA) statistical software package.

\section{Results}

Hypoxia increased VEGF production and Neuropilin-1 expression. 4T1 and MDA-MB-231 mammary adenocarcinoma cells were cultured under normoxic or hypoxic growth conditions for $24 \mathrm{~h}$. Hypoxia significantly increased VEGF production by $4 \mathrm{~T} 1(36.30 \pm 2.92 \mathrm{pg} \mathrm{VEGF} / \mu \mathrm{g}$ protein, Fig. 1A) 
A.

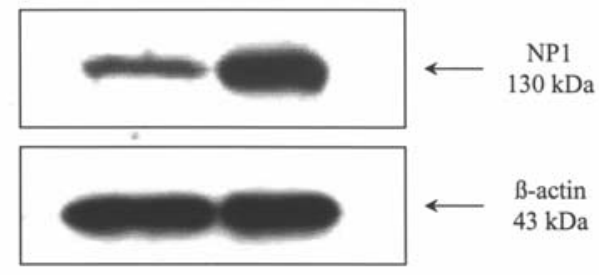

B.
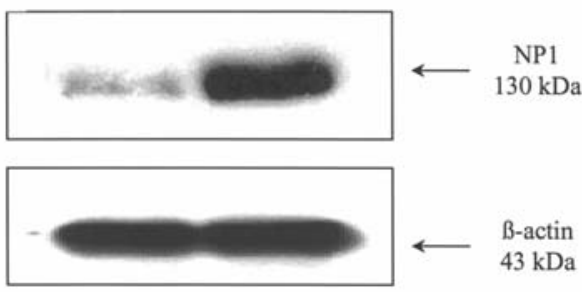

C.

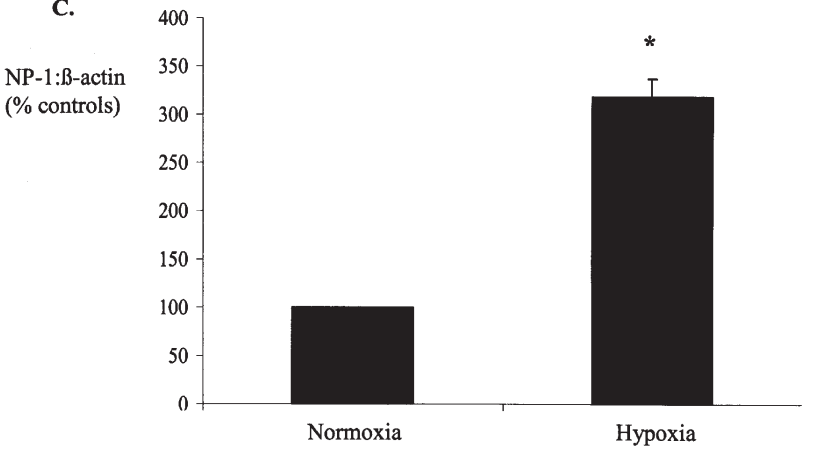

D.

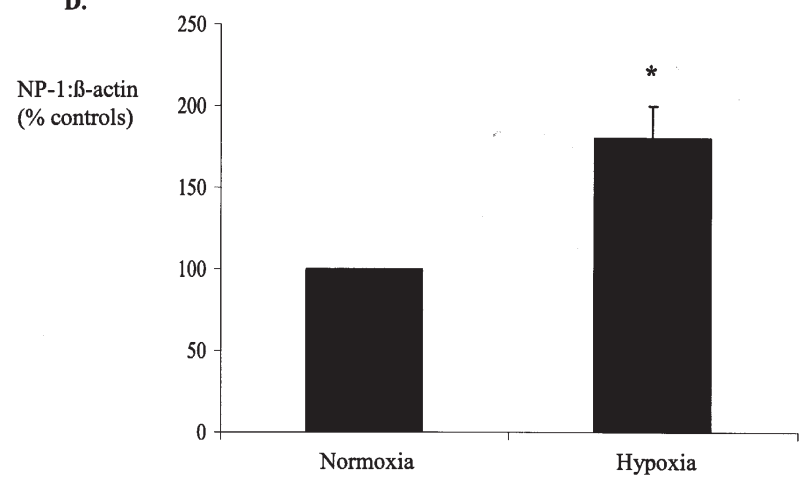

Figure 2. Neuropilin-1 (NP1) receptor protein is expressed on 4T1 (A) and MDA-MB-231 (B) tumour cells. Cells were cultured under normoxia (21\% $\left.\mathrm{O}_{2}\right)$ or hypoxia $\left(2 \% \mathrm{O}_{2}\right)$ for $24 \mathrm{~h}$ and NP1 receptor expression was examined in both cell lines by Western blotting. Blots were stripped and re-probed for $\beta$-actin in both cell lines to control for equal loading. Blots shown are representative of three independent experiments. Densitometric analysis of NP1 expression in 4T1 (C) and MDA-MB-231 (D) tumour cells. NP1 expression was normalised to $\beta$-actin and expressed as a percentage of normoxic controls which were taken as $100 \%$. Data are expressed as the mean \pm SEM. Statistical analysis was performed using an unpaired Student's t-test ( ${ }^{*} \mathrm{p}<0.01$, hypoxia vs normoxia, $\mathrm{n}=3$ ).

and MDA-MB-231 (12.18 $\pm 0.265 \mathrm{pg} \mathrm{VEGF/ \mu g} \mathrm{protein,}$ Fig. 1B) cells relative to normoxia $(4 \mathrm{~T} 1,14.6 \pm 0.318 \mathrm{pg}$ $\mathrm{VEGF} / \mu \mathrm{g}$ protein; MDA-MB-231, 7.35 $\pm 0.45 \mathrm{pg} \mathrm{VEGF} / \mu \mathrm{g}$ protein; $\mathrm{p}<0.05)$. We have previously demonstrated that hypoxia-induced VEGF can be prevented by anti-VEGF
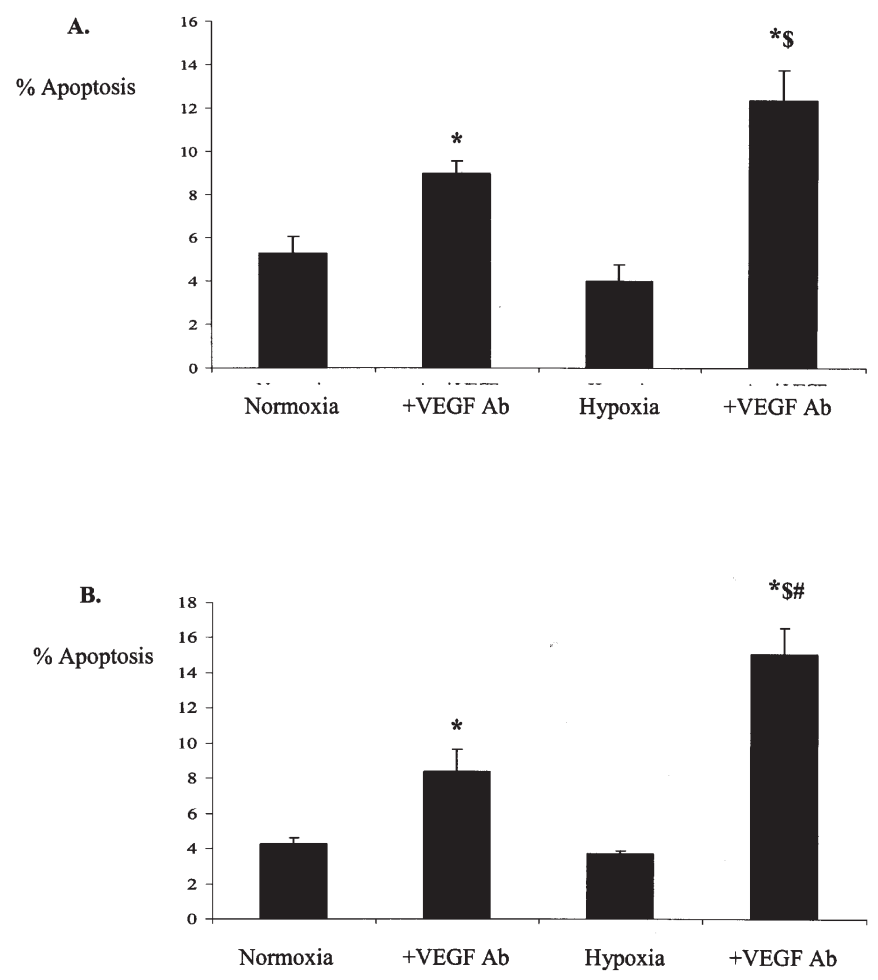

Figure 3. VEGF blockade induced tumour cell apoptosis. 4T1 (A) and MDA-MB-231 (B) cells were cultured in chamber slides for $24 \mathrm{~h}$ under normoxia $\left(21 \% \mathrm{O}_{2}\right)$ or hypoxia $\left(2 \% \mathrm{O}_{2}\right)$ in the presence or absence of VEGF neutralising antibodies $(1 \mu \mathrm{g} / \mathrm{ml})$. Cells were stained using TUNEL and apoptotic tumour cells were counted in five high-power fields per sample (x400 magnification). Data expressed as mean \pm SEM. Statistical analysis was carried out by ANOVA with Scheffe post-hoc correction $\left({ }^{*} \mathrm{p}<0.05\right.$, normoxia + VEGF Ab vs normoxia; ${ }^{\$} \mathrm{p}<0.01$, hypoxia + VEGF Ab vs hypoxia; ${ }^{\#} \mathrm{p}<0.05$ hypoxia + VEGF Ab vs normoxia + VEGF Ab, n=3)

antibodies. More recently, we have shown that 4T1 and MDAMB-231 cells express NP1 but not KDR/Flk-1 (VEGFR2) (23). In addition to increasing VEGF production, hypoxia also increased expression of NP1 in both 4T1 (Fig. 2A) and MDAMB-231 (Fig. 2B) cells. Densitometric analysis confirmed a significant increase in NP1 expression under hypoxia in both tumour cell lines (4T1, 319 $\pm 31.32 \%$, Fig. 2C; MDA-MB-231, $180 \pm 17.96 \%$, Fig. 2D).

VEGF blockade induced breast tumour cell apoptosis. To examine whether VEGF protects tumour cells from apoptosis under hypoxic conditions, cells were cultured in chamber slides and treated for $24 \mathrm{~h}$ with anti-VEGF antibodies under normoxia $\left(21 \% \mathrm{O}_{2}\right)$ or hypoxia $\left(2 \% \mathrm{O}_{2}\right)$. Apoptosis was determined using the TUNEL assay. Serum levels were reduced from $10 \%$ to $1 \%$ to increase the basal levels of apoptosis. Relative to normoxic controls, hypoxia had little effect on tumour cell apoptosis. Treatment of cells under normoxic conditions with anti-VEGF antibodies resulted in a significant increase in apoptosis in both cell lines relative to controls $(4 \mathrm{~T} 1,9.0 \pm 0.54 \%$ vs $5.3 \pm 0.78 \%$, Fig. 3A; MDAMB-231, $8.42 \pm 1.26 \%$ vs $4.28 \pm 0.32 \%$, Fig. 3B). Inclusion of VEGF neutralising antibodies under hypoxia also resulted in a significant induction of apoptosis in both cell lines, and to a greater extent under hypoxia than normoxia $(4 \mathrm{~T} 1,12.36 \pm 1.39 \%$ vs $9.0 \pm 0.54 \%$; MDA-MB-231, $15.11 \pm 1.47 \%$ vs $8.42 \pm 1.26 \%$ ). 
A.

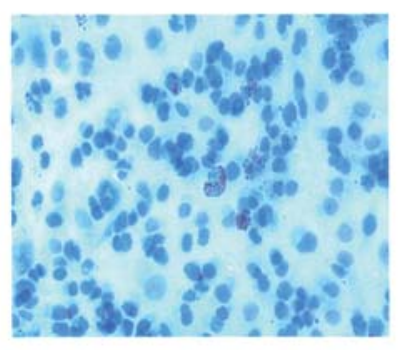

Hypoxia

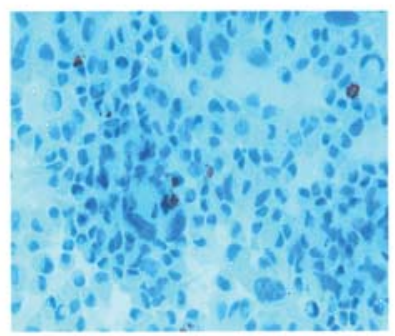

Normoxia+VEGF Ab

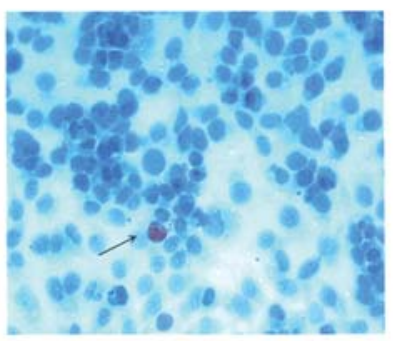

Hypoxia+VEGF Ab

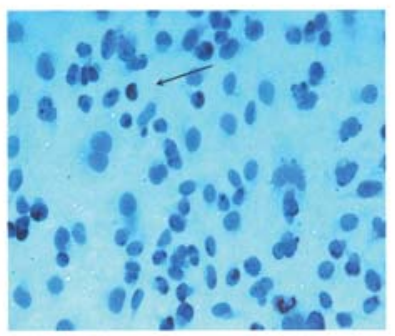

B.

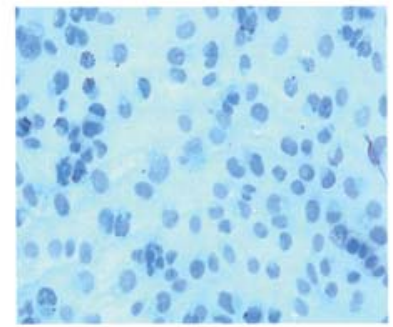

Hypoxia

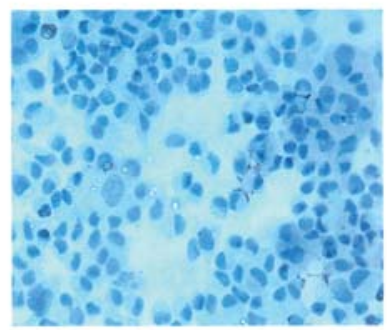

Normoxia+VEGF Ab

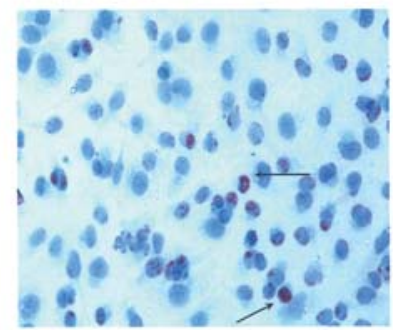

Hypoxia+VEGF Ab

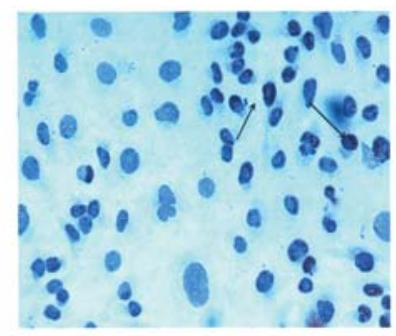

Figure 4. TUNEL staining of 4T1 (A) and MDA-MB-231 (B) tumour cells. Cells were incubated for 24 h under normoxia $\left(21 \% \mathrm{O}_{2}\right)$ or hypoxia (2\% $\left.\mathrm{O}_{2}\right)$ in the presence or absence of VEGF neutralising antibodies $(1 \mu \mathrm{g} / \mathrm{ml})$. Apoptotic tumour cells (brown) were identified by TUNEL staining and morphology, as indicated by arrows (original magnification $\mathrm{x} 400$ ).

Representative TUNEL staining of 4T1 (Fig. 4A) and MDAMB-231 cells (Fig. 4B) are shown. Increased numbers of TUNEL-positive (brown) cells with apoptotic morphology were clearly visible in cells treated with anti-VEGF antibodies under both normoxia and hypoxia. Blocking either baseline VEGF (normoxia + VEGF Ab) or hypoxia-induced VEGF (hypoxia + VEGF Ab) increased tumour cell apoptosis, demonstrating a role for VEGF as a tumour cell survival factor, particularly under hypoxic stress.

Effect of VEGF blockade on Bcl-2 and Bad expression. Expression of the anti-apoptotic protein Bcl-2 and the proapoptotic protein Bad was examined under normoxia and hypoxia with and without VEGF blockade (VEGF neutralising antibody). Hypoxia $\left(2 \% \mathrm{O}_{2}\right)$ resulted in a significant increase in Bcl-2 relative to normoxia in 4T1 and MDA-MB-231 cells

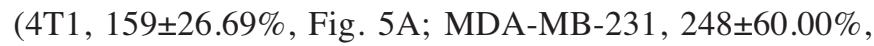
Fig. 5B). Under normoxic conditions, anti-VEGF antibodies had no significant effect on Bcl-2 expression in either cell line. VEGF neutralising antibody significantly reduced hypoxiainduced Bcl-2 in both cell lines $(4 \mathrm{~T} 1,107 \pm 14.74 \%$ vs $159 \pm 26.69 \%$; MDA-MB-231, $171 \pm 33.84 \%$ vs $248 \pm 22.81 \%$ ). These data demonstrate that hypoxia-induced Bcl-2 expression can be attenuated by VEGF blockade, particularly in MDAMB-231 tumour cells.

The effect of VEGF neutralisation on the expression of the pro-apoptotic protein Bad was then examined. Under normoxia, VEGF neutralising antibodies had no effect on Bad protein expression in 4T1 and MDA-MB-231 cells (Fig. 5C and $\mathrm{D}$, respectively). Hypoxia decreased Bad expression

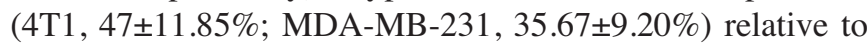
normoxia (normoxic controls were taken as $100 \%$ ). VEGF neutralising antibody increased Bad protein expression under hypoxic conditions relative to hypoxic controls (lane 4) (4T1,
$72 \pm 6.51 \%$ vs $47 \%$; MDA-MB-231, $64.67 \pm 1.76 \%$ vs $35.67 \%$ ), although not to the level expressed in normoxic controls. VEGF blockade had no effect on expression of the antiapoptotic protein, Bcl-2, or the pro-apoptotic protein, Bad, in 4T1 and MDA-MB-231 breast tumour cells under normoxia. However, under hypoxic conditions, VEGF blockade affected both sides of the apoptotic balance, decreasing Bcl-2 and increasing Bad. These data suggest that different signalling pathways may exist in 4T1 and MDA-MB-231 tumour cells, by which VEGF blockade induces apoptosis under normoxia and hypoxia.

Neutralising antibodies to VEGF abrogated hypoxia-induced phosphorylation of Akt. Our data show that VEGF blockade induces apoptosis and alters the $\mathrm{Bcl}-2 / \mathrm{Bad}$ ratio in breast tumour cells. VEGF signalling mechanisms were examined in 4T1 and MDA-MB-231 cells. Akt phosphorylation in response to recombinant VEGF and/or neutralising antibody to VEGF under normoxia and hypoxia was therefore examined. Akt is activated by a dual regulatory mechanism that requires both translocation to the plasma membrane and phosphorylation at Thr308 and Ser473 (24). Although Thr308 phosphorylation is sufficient for Akt activation (25), maximal activation of Akt also requires phosphorylation of Ser473 (26). We established that maximum phosphorylation of Akt in response to VEGF $(100 \mathrm{ng} / \mathrm{ml})$ occurred after $30 \mathrm{~min}$ (data not shown). This induction of Akt phosphorylation by VEGF was inhibited by wortmannin, indicating that VEGF-induced phosphorylation of Akt occurred via PI3K.

4T1 tumour cells were cultured under normoxia and hypoxia in the presence or absence of recombinant VEGF, the PI3K inhibitor, wortmannin, in combination with recombinant VEGF, neutralising antibody to VEGF or a combination of recombinant VEGF and neutralising antibodies to VEGF, 
A.

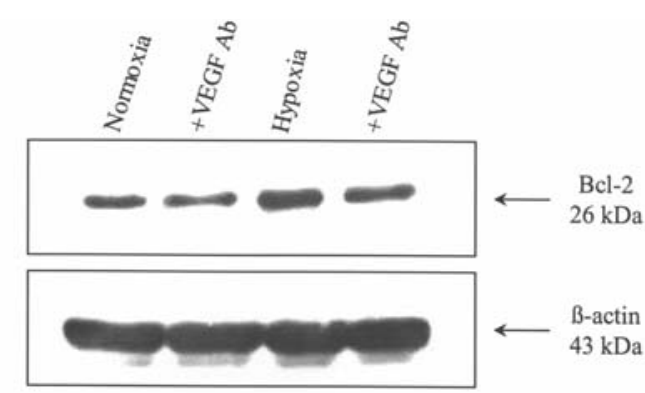

B.

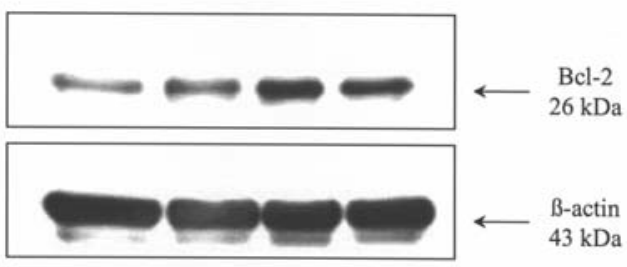

C.
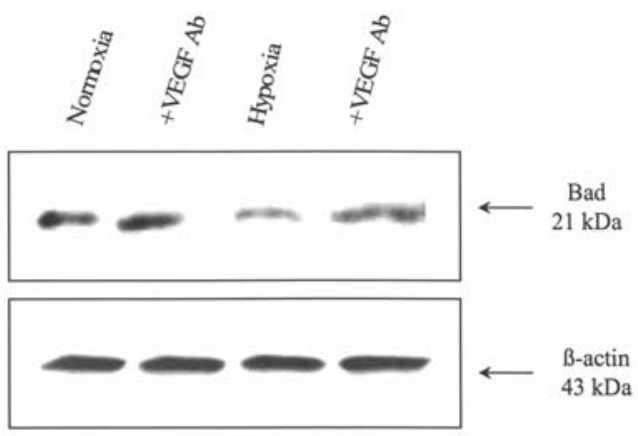

D.

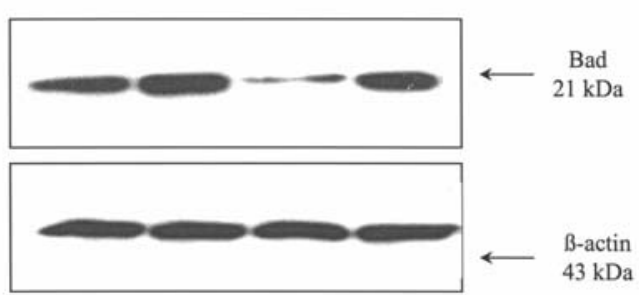

Figure 5. Effect of VEGF neutralising antibodies on Bcl-2 and Bad protein expression in 4T1 and MDA-MB-231 tumour cells under normoxia (21\% $\mathrm{O}_{2}$ ) or hypoxia $\left(2 \% \mathrm{O}_{2}\right)$. Bcl-2 expression in $4 \mathrm{~T} 1$ and MDA-MB-231 cells (A and $\mathrm{B}$, respectively) and Bad protein expression (C and D, respectively) were examined under normoxia and hypoxia in the presence or absence of VEGF neutralising antibodies $(1 \mu \mathrm{g} / \mathrm{ml})$ for $24 \mathrm{~h}$. Blots were stripped and re-probed for $\beta$-actin to normalise for loading differences. Blots shown are representative of three independent experiments. Densitometric analysis of Bcl-2 ( $\mathrm{E}$ and $\mathrm{F}$ ) and $\mathrm{Bad}(\mathrm{G}$ and $\mathrm{H})$ protein expression in $4 \mathrm{~T} 1$ and MDA-MB-231 tumour cells relative to $B$-actin expression. Protein expression was normalised to $B$-actin and expressed as a percentage of normoxic controls which were taken as $100 \%$. Data are expressed as the mean \pm SEM. Statistical analysis was performed by ANOVA with Scheffe post-hoc correction $\left({ }^{*} \mathrm{p}<0.05\right.$, hypoxia vs normoxia, ${ }^{\$} \mathrm{p}<0.05$, hypoxia + VEGF Ab vs hypoxia, $n=3$ ).

for $30 \mathrm{~min}$ in order to examine their effect on Akt phosphorylation. Blots were probed with a monoclonal antibody which recognises Akt phosphorylation at Ser473. Relative to controls, both recombinant VEGF or hypoxia increased Akt phosphorylation in 4T1 cells (Fig. 6). This increase in Akt phosphorylation under hypoxia may be due to hypoxia-induced VEGF. Wortmannin blocked Akt phosphorylation to below control levels under normoxia (Fig. 6A) and reduced the
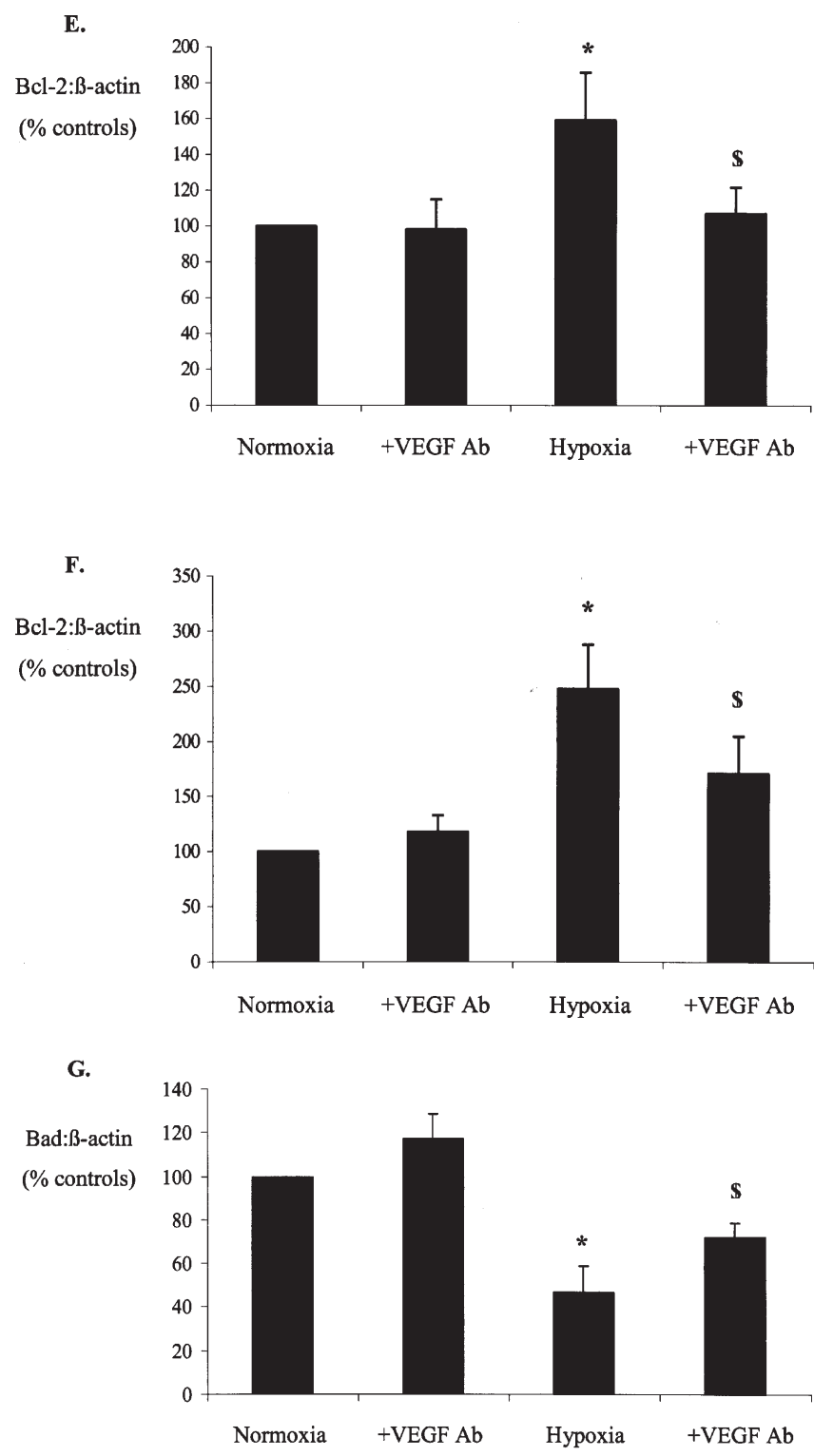

H.

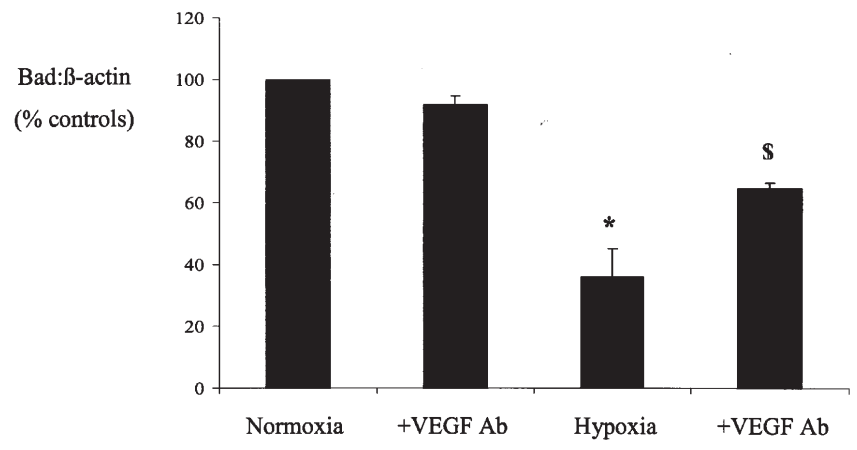

phosphorylation induced by hypoxia (Fig. 6B). It may be possible that the concentration of wortmannin used $(500 \mathrm{nM})$ may have been insufficient to completely block the increase in Akt phosphorylation observed under hypoxia. VEGF neutralising antibody inhibited Akt phosphorylation in 4T1 cells, an effect which was reversed by the addition of recombinant VEGF. Under hypoxia, VEGF neutralising antibody also blocked Akt phosphorylation but recombinant VEGF 
A.
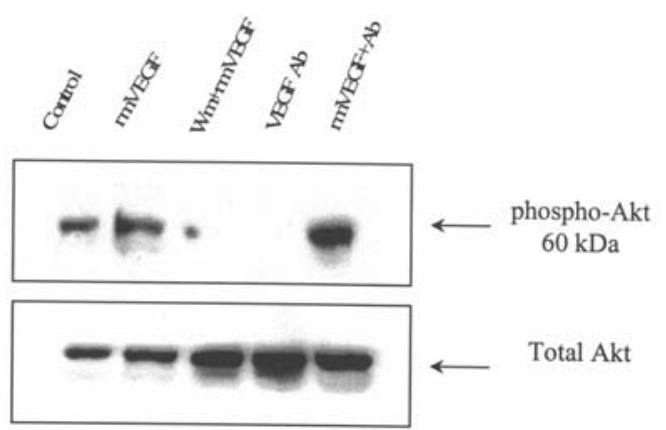

B.

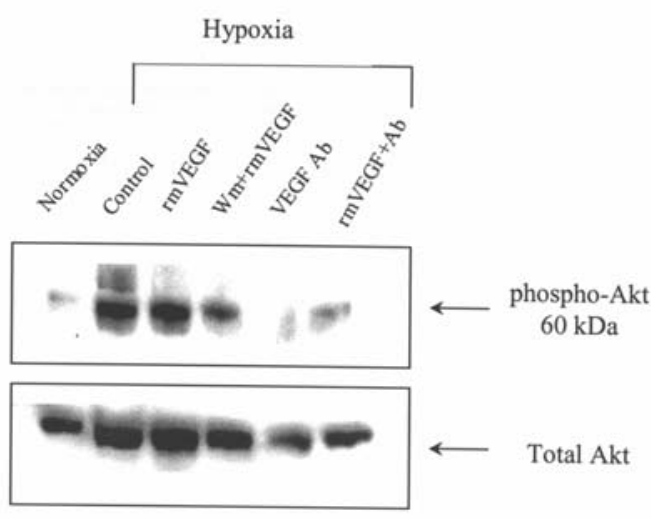

Figure 6. VEGF blockade inhibited the hypoxia-induced Akt phosphorylation of breast tumor cells. 4T1 tumour cells were cultured under normoxia (21\% $\left.\mathrm{O}_{2}\right)(\mathrm{A})$ and hypoxia $\left(2 \% \mathrm{O}_{2}\right)(\mathrm{B})$ for $30 \mathrm{~min}$ in the presence of $100 \mathrm{ng} / \mathrm{ml}$ recombinant VEGF (rmVEGF), $500 \mathrm{nM}$ wortmannin (Wm), $1 \mu \mathrm{g} / \mathrm{ml}$ VEGF neutralising antibodies (VEGF Ab) or recombinant VEGF in combination with VEGF neutralising antibodies (rmVEGF + VEGF Ab). Akt phosphorylation was examined by Western blotting using an anti-phospho-Akt (p-Ser473)specific monoclonal antibody. Blots were stripped and reprobed for total Akt.

only partially reversed this effect. These data suggest that VEGF pro-survival signals in mammary adenocarcinoma cells are mediated via the PI3K/Akt signalling pathway, promoting phosphorylation of Akt. Moreover, these results suggest that the induction of 4T1 tumour cell apoptosis by VEGF blockade is at least, in part, mediated by preventing VEGF-induced Akt phosphorylation, thereby blocking the anti-apoptotic effects of VEGF under hypoxia. Although recombinant VEGF could overcome the inhibition of Akt phosphorylation in response to VEGF neutralisation under normoxia, this effect was only partially seen by VEGF blockade under hypoxia.

\section{Discussion}

Tumours commonly outgrow their blood supply resulting in hypoxic areas that stimulate the release of angiogenic cytokines such as VEGF. This hypoxic stress also exerts a selective pressure within tumours, supporting the expansion of cells with reduced apoptotic potential (27). VEGF is one of the most potent pro-angiogenic growth factors identified to date and has been shown to protect endothelial cells from apoptosis by inducing the anti-apoptotic protein, Bcl-2 (28), thereby prolonging the survival of endothelial cells and sustaining angiogenesis. VEGF protects haematopoietic cells and some leukemic cell lines from chemotherapy-induced apoptosis, an effect that involves the induction of Mcl-1, an anti-apoptotic member of the Bcl-2 family (29). The role of VEGF as a tumour cell survival factor via induction of Bcl-2 and inhibition of apoptosis has been reported in a number of tumour types such as neuroblastoma (30), leukaemia (17) and breast carcinoma cells $(18,19)$.

As 4T1 and MDA-MB-231 cells constitutively express VEGF, blocking VEGF using neutralising antibodies to VEGF was used to examine VEGF-mediated inhibition of tumour cell apoptosis. In this study, anti-VEGF antibodies had a direct effect on murine and human tumour cells, inducing significant apoptosis under normoxia, but to a greater extent under hypoxia. Under normoxic growth, tumour cells are not subjected to stress and therefore, there is a minimum requirement for VEGF. On the contrary, cells that are grown under hypoxia, as in a solid tumour, are stressed. As a result, there is an increase in VEGF expression, in which case tumour cells may become dependent on VEGF for survival. VEGF neutralising antibodies partially blocked hypoxia-induced Bcl-2, suggesting a mechanism whereby VEGF-induced expression of Bcl-2 may enhance the survival of mammary adenocarcinoma cells and, more importantly, in hypoxia, areas of solid tumours. These observations indicate that the hypoxia-induced expression of Bcl-2 observed in 4T1 and MDA-MB-231 breast tumour cells, was mediated through VEGF. We investigated the mechanisms underlying VEGFmediated inhibition of tumour cell apoptosis. Under normoxia, VEGF blockade had no effect on the expression of the antiapoptotic protein, Bcl-2, or the pro-apoptotic protein, Bad. However, under hypoxic conditions, VEGF blockade affected the balance between these anti- and pro-apoptotic Bcl-2 family members, suggesting that alterations in these proteins underlie VEGF-mediated inhibition of tumour cell apoptosis, particularly under low oxygen tensions. The decrease in hypoxia-induced $\mathrm{Bcl}-2$ and increase in Bad protein expression in response to VEGF blockade suggest a role for these cell death proteins as mediators of the pro-survival effect of VEGF on hypoxic tumour cells. Other studies have demonstrated that hypoxia protects breast tumour cells from apoptosis induced by serum deprivation as a function of the integrin, $\alpha 631$ (31) and highlights the potential function for such integrins in stimulating VEGF transcription and providing a survival advantage for breast carcinoma cells under hypoxia. Such observations are in agreement with our findings that breast carcinoma cells depend on the autocrine effects of VEGF on survival, particularly under low oxygen tensions and suggest that signalling pathways by which VEGF blockade induces apoptosis may be different under normoxic and hypoxic growth conditions.

Phospho-Akt promotes cell survival by inhibiting apoptosis. Phospho-Akt (Ser473) has been shown to specifically phosphorylate Bad, resulting in the inactivation of its pro-apoptotic function (32). Our results show that, similar to its effects on endothelial cells, VEGF phosphorylates Akt via the PI3K signalling pathway. Decreased Akt phosphorylation in response to VEGF blockade under normoxia and hypoxia is therefore a possible mechanism whereby anti-VEGF strategies overcome the autocrine survival effects of VEGF in breast tumour cells and induce apoptosis. 
NP1 was originally identified as a receptor for the collapsin/ semaphorin family that mediates neuronal cell guidance (33). More recently, it has been identified as an isoform-specific receptor for $\mathrm{VEGF}_{165}$ in endothelial cells and some tumour cells (34). When co-expressed in cells expressing KDR/ VEGFR2 (kinase insert domain receptor), NP1 enhances the binding of $\mathrm{VEGF}_{165}$ to $\mathrm{KDR}$ and $\mathrm{VEGF}_{165}$-mediated chemotaxis. A role for VEGF in preventing tumour cell apoptosis is further supported by reports demonstrating that overexpression of soluble NP1, which prevents VEGF binding to cell surface receptors in tumour cells, is associated with tumour cell apoptosis (35). The importance of the NP1 receptor in maintaining survival of breast carcinoma cells and haematopoietic stem cells has been described $(36,37)$.

A number of studies have examined the regulation of the VEGF receptors, Flt-1/VEGFR-1 (fms-like tyrosine kinase), KDR and NP1 by hypoxia. The hypoxic response in vivo was demonstrated to differentially regulate the distribution of VEGF and its receptors Flt-1 and KDR in specific cell types and organs (38). Expression of Flt-1, but not KDR, was induced by hypoxia in endothelial cells of the lung, heart, brain, kidney and liver. In human astrocytoma cells, hypoxia was shown to decrease NP1 expression (39). We show that both VEGF and NP1 are upregulated by hypoxia. As NP1 has a short intracellular domain and cannot transduce intracellular signals alone, it has been suggested that complex formation of NP1 with a co-receptor is necessary for signal transduction. In neuronal cells, the effects of class III semaphorins are mediated, at least in part, by NP1 and NP2, where NP1 is a high-affinity receptor for Sema3A (40). Previous studies have suggested that, while NP1 is necessary and sufficient for growth cone binding of Sema3A, NP1 does not, by itself, transmit a signal to the cytoplasmic domain of the growth cone (41). Therefore, since the Neuropilins lack a functional cytoplasmic signalling domain, class III semaphorins bind to NP/Plexin receptor complexes. In doing so, the plexins transduce the signal to downstream cytoplasmic molecules (42). At present, it is unclear as to the mechanism of NP1 signalling in the absence of the classical VEGF tyrosinekinase receptors, Flt-1 and KDR, as the NP1 receptor lacks a cytoplasmic signalling domain. We have previously shown that NP1 plays an essential role in autocrine anti-apoptotic signalling by VEGF in 4T1 and MDA-MB-231 tumour cells which do not express the VEGF tyrosine kinase receptor, KDR (23). Using a peptide corresponding to the NP1 binding site on VEGF $_{165}$, NP1 blockade induced tumour cell and endothelial cell apoptosis. Accumulating data also suggest a role for NP1 in VEGF-dependent survival in endothelial, tumour and neuronal cells $(18,34,43)$. Our findings demonstrate that NP1 is upregulated under hypoxia, which increases VEGF. Because survival during hypoxia depends on VEGF, it is possible that NP1 enhances the VEGF-survival effect in these cells, where hypoxia stimulates VEGF-dependent signalling not only by upregulation of the VEGF ligand, but also by functional upregulation of the NP1 receptor.

Evidence that VEGF is an autocrine survival factor for tumour cells has important implications for the efficacy of anticancer therapies. Decreased apoptotic potential or resistance to apoptosis is well recognised in virtually all known human malignancies and provides malignant cells with a selective growth advantage, allowing proliferation even in the face of radiation and chemotherapy. Moreover, both radiation and chemotherapy induce VEGF which may inadvertently protect some cells from apoptosis. Blocking autocrine anti-apoptotic VEGF signalling may account, in part, for the synergistic effect of anti-VEGF strategies in combination with ionising radiation and chemotherapy, rendering tumour cells more susceptible to apoptosis.

\section{Acknowledgements}

This study was supported by a Health Research Board Grant RP182/2000, Higher Education Authority, Cycle II and RCSI Research Committee Grant 014/02 to JH.

\section{References}

1. Brizel DM, Sibley GS, Prosnitz LR, Scher RL and Dewhirst MW: Tumor hypoxia adversely affects the prognosis of carcinoma of the head and neck. Int J Radiat Oncol Biol Phys 38: 285-289, 1997.

2. Nordsmark M, Overgaard M and Overgaard J: Pretreatment of oxygenation predicts radiation response in advanced squamous cell carcinoma of the head and neck. Radiother Oncol 41: 31-39, 1996.

3. Brizel DM, Scully SP, Harrelson JM, Layfield LJ, Bean JM, Prosnitz LR and Dewhirst MW: Tumor oxygenation predicts for the likelihood of distant metastases in human soft tissue sarcoma. Cancer Res 56: 941-943, 1996.

4. Hockel M, Schlenger K, Aral B, Mitze M, Schaffer U and Vaupel P: Association between tumor hypoxia and malignant progression in advanced cancer of the uterine cervix. Cancer Res 56: 4509-4515, 1996.

5. Airley RE, Phillips RM, Evans AE, et al: Hypoxia-regulated glucose transporter Glut-1 may influence chemosensitivity to some alkylating agents: Results of EORTC (First Translational Award) study of the relevance of tumour hypoxia to the outcome of chemotherapy in human tumour-derived xenografts. Int J Oncol 26: 1477-1484, 2005.

6. Yokoi K and Fidler IJ: Hypoxia increases resistance of human pancreatic cancer cells to apoptosis induced by gemcitabine. Clin Cancer Res 10: 2299-2306, 2004.

7. Lee CG, Heijn M, di Tomaso E, et al: Anti-vascular endothelial growth factor treatment augments tumor radiation response under normoxic or hypoxic conditions. Cancer Res 60: 5565-5570, 2004.

8. Jain RK: Vascular and interstitial barriers to delivery of therapeutic agents in tumors. Cancer Metastasis Rev 9: 253-266, 1990.

9. Van den Eynden GG, Van der Auwere I, Van Laere SJ, et al: Angiogenesis and hypoxia in lymph node metastases is predicted by the angiogenesis and hypoxia in the primary tumour in patients with breast cancer. Br J Cancer 93: 1128-1136, 2005.

10. Koshikawa N, Iyozumi A, Gassmann M and Takenaga K: Constitutive upregulation of hypoxia-inducible factor-1-alpha mRNA occurring in highly metastatic lung carcinoma cells leads to vascular endothelial growth factor overexpression upon hypoxia exposure. Oncogene 22: 6717-6724, 2003.

11. Dachs GU and Stratford IJ: The molecular response of mammalian cells to hypoxia and the potential for exploitation in cancer therapy. Br J Cancer 74: 126-132, 1996.

12. Rofstad EK and Danielsen T: Hypoxia-induced metastasis of human melanoma cells: involvement of vascular endothelial growth factor-mediated angiogenesis. Br J Cancer 80: 1697-1707, 1999.

13. Asano M, Yukita A and Suzuki H: Wide spectrum of antitumor activity of a neutralizing monoclonal antibody to human vascular endothelial growth factor. Jpn J Cancer Res 90: 93-100, 1999.

14. Kanai T, Konno H, Tanaka T, et al: Anti-tumor and antimetastatic effects of human vascular endothelial growth factor neutralizing antibody on human colon and gastric carcinoma xenotransplanted orthotopically into nude mice. Int J Cancer 77: 933-936, 1998.

15. Kim KJ, Li B, Winer J, Armanini M, Gillet N, Phillips HS and Ferrara N: Inhibition of vascular endothelial growth factorinduced angiogenesis suppresses tumor growth in vivo. Nature 362: 841-844, 1993. 
16. Grunstein J, Roberts WG, Mathieu-Costello O, Hanahan D and Johnson RS: Tumor-derived expression of vascular endothelial growth factor is a critical factor in tumor expansion and vascular function. Cancer Res 59: 1592-1598, 1999.

17. Dias S, Shmelkov SV, Lam G and Rafii S: $\operatorname{VEGF}(165)$ promotes survival of leukemic cells by Hsp90-mediated induction of Bcl-2 expression and apoptosis inhibition. Blood 99: 2532-2540, 2002.

18. Bachelder RE, Crago A, Chung J, Wendt MA, Shaw LM, Robinson $\mathrm{G}$ and Mercurio AM: Vascular endothelial growth factor is an autocrine survival factor for neuropilin-expressing breast carcinoma cells. Cancer Res 61: 5736-5740, 2001.

19. Pidgeon GP, Barr MP, Harmey JH, Foley DA and BouchierHayes DJ: Vascular endothelial growth factor (VEGF) upregulates BCL-2 and inhibits apoptosis in human and murine mammary adenocarcinoma cells. Br J Cancer 85: 273-278, 2001.

20. Nor JE, Christensen J, Liu J, Peters M, Mooney DJ, Strieter RM and Polverini PJ: Upregulation of Bcl-2 in microvascular endothelial cells enhances intratumoral angiogenesis and accelerates tumour growth. Cancer Res 61: 2183-2188, 2001.

21. Hutchings $\mathrm{H}$, Ortega $\mathrm{N}$ and Plouet J: Extracellular matrix-bound vascular endothelial growth factor promotes endothelial cell adhesion, migration and survival through integrin ligation. FASEB J 17: 1520-1522, 2003.

22. Cai J, Ahmad S, Jiang WG, Huang J, Kontos CD, Boulton M and Ahmed A: Activation of vascular endothelial growth factor receptor-1 sustains angiogenesis and Bcl-2 expression via the phosphatidylinositol 3-kinase pathway in endothelial cells. Diabetes 52: 2959-2968, 2003.

23. Barr MP, Byrne AM, Duffy AM, Condron CM, Devocelle M, Harriott P, Bouchier-Hayes DJ, et al: A peptide corresponding to the neuropilin-1 binding site on $\operatorname{VEGF(165)~induces~apoptosis~}$ of neuropilin-1-expressing breast tumour cells. Br J Cancer 92: 328-333, 2005.

24. Andjelkovic M, Alessi DR, Meier R, et al: Role of translocation in the activation and function of protein kinase B. J Biol Chem 272: 31515-31524, 1997.

25. Stokoe D, Stephens LR, Copeland T, et al: Dual role of phosphatidylinositol-3,4,5-triphosphate in the activation of protein kinase B. Science 277: 567-570, 1997.

26. Alessi DR, James SR, Downes CP, Holmes AB, Gaffney PR, Reese CB and Cohen P: Characterization of a 3-phosphoinositidedependent protein kinase which phosphorylates and activates protein kinase B alpha. Curr Biol 7: 261-269, 1997.

27. Graeber TG, Osmanian C, Jacks T, Housman DE, Koch CJ, Lowe SW and Giaccia AJ: Hypoxia-mediated selection of cells with diminished apoptotic potential in solid tumours. Nature 379: 88-91, 1996.

28. Nor JE, Christensen J, Mooney DJ and Polverini PJ: Vascular endothelial growth factor (VEGF)-mediated angiogenesis is associated with enhanced endothelial cell survival and induction of Bcl-2 expression. Am J Pathol 154: 375-384, 1999.
29. Katoh O, Takahashi T, Oguri T, et al: Vascular endothelial growth factor inhibits apoptotic death in haematopoietic cells after exposure to chemotherapeutic drugs by inducing MCL-1 acting as an antiapoptotic factor. Cancer Res 58: 5565-5569, 1998 .

30. Beierle EA, Strande LF and Chen MK: VEGF upregulates Bcl-2 expression and is associated with decreased apoptosis in neuroblastoma cells. J Pediatr Surg 37: 467-471, 2002.

31. Chung J, Yoon S, Datta K, Bachelder RE and Mercurio AM: Hypoxia-induced vascular endothelial growth factor transcription and protection from apoptosis are dependent on $\alpha 631$ integrin in breast carcinoma cells. Cancer Res 64: 4711-4716, 2004.

32. Nunez G and Del Paso L: Linking extracellular survival signals and the apoptotic machinery. Curr Opin Neurobiol 8: 613-618, 1998 .

33. Fujisawa H and Kitsukawa T: Receptors for collapsin/ semaphorins. Curr Opin Neurobiol 8: 587-592, 1998.

34. Soker S, Takashima S, Miao HQ, Neufeld G and Klagsbrun M: Neuropilin-1 is expressed by endothelial and tumor cells as an isoform-specific receptor for vascular endothelial growth factor. Cell 92: 735-745, 1998.

35. Gagnon ML, Bielenberg DR, Gechtman Z, Miao HQ, Takashima S, Soker S and Klagsbrun M: Identification of a natural soluble neuropilin-1 that binds vascular endothelial growth factor: in vivo expression and anti-tumor activity. Proc Natl Acad Sci USA 97: 2573-2578, 2000.

36. Bachelder RE, Wendt MA and Mercurio AM: Vascular endothelial growth factor promotes breast carcinoma invasion in an autocrine manner by regulating the chemokine receptor CXCR4. Cancer Res 62: 7203-7206, 2002.

37. Gerber HP, Malik AK, Solar GP, et al: Vascular endothelial growth factor regulates hematopoietic stem cell survival by an internal autocrine loop mechanism. Nature 417: 954-958, 2002.

38. Marti HH and Risau W: Systemic hypoxia changes the organspecific distribution of vascular endothelial growth factor and its receptors. Proc Natl Acad Sci USA 95: 15809-15814, 1998.

39. Ding H, Wu X, Roncari L, Lau N, Shannon P, Nagy A and Guha A: Expression and regulation of neuropilin-1 in human astrocytomas. Int J Cancer 88: 584-592, 2000.

40. He Z and Tessier-Lavigne M: Neuropilin is a receptor for the axonal chemorepellent Semaphorin III. Cell 90: 739-751, 1997.

41. Kolodkin AL, Levengood DV, Rowe EG, Tai YT, Giger RJ and Ginty DD: Neuropilin is a semaphorin III receptor. Cell 90: 753-762, 1997.

42. Takahashi T, Fournier A, Nakamura F, et al: Plexin-neuropilin-1 complexes form functional semaphorin-3A receptors. Cell 99: 59-69, 1999.

43. Oosthuyse B, Moons L, Storkebaum E, et al: Deletion of the hypoxia-response element in the vascular endothelial growth factor promoter causes motor neuron degeneration. Nat Genet 28: 131-138, 2001. 